\title{
Fabrication and Characterization of Onggi Filter for Appropriate Water Treatment Technology
}

\author{
Joon-Hong Park, Jin-Ho Kim, Woo-Seok Cho, Kyu-Sung Han, and Kwang-Taek Hwang ${ }^{\dagger}$ \\ Ceramicware Center, Korea Institute of Ceramic Engineering and Technology, Icheon 17303, Korea \\ (Received October 6, 2016; Revised February 13, 2017; Accepted February 22, 2017)
}

\begin{abstract}
In underdeveloped countries, many people suffer from water shortage due to the absence of water supply service. Although water purifiers have provided support in such situations, it is not easy to maintain water filters without a continuous supply of consumable filters. To obtain a sustainable drinking water source, appropriate technology of water treatment is necessary. Herein, a low cost water purification system was developed using natural raw materials. A non-electric water treatment system was developed using filtration through an Onggi filter, which is a type of Korean traditional earthenware with a microporous surface. The porosity and flux of the prepared Onggi filter were $29.06 \%$ and $31.63 \mathrm{LMH}$, respectively. After purification of water with total dissolved solids of $10.4 \mathrm{mg} / \mathrm{L}$ and turbidity of $100 \mathrm{NTU}$, the total dissolved solids and turbidity of the water treated using the Onggi filter decreased by $12 \%$ and $99.8 \%$, respectively.
\end{abstract}

Key words : Appropriate technology, Onggi filter, Raw material, Non-electric water treatment system

\section{Introduction}

$\mathbf{I}_{\mathrm{d}}^{\mathrm{n}}$ developing countries like Cambodia, a shortage of drinking water due to lack of waterworks/sewer systems despite abundant water resources is causing serious problems. In fact, Cambodian households collect rainwater during rainy periods to use for drinking, while drawing water from puddles and keeping it in containers during the dry season and waiting for impurities in the water to settle naturally before using the stored water for drinking. However, suspended particulate matter contained in water from a puddle does not settle easily, and viruses such as E. coli that may exist in the water can cause water-borne diseases, making the lives of people including children in developing countries very difficult. Against this backdrop, there is a growing interest in appropriate technology or "warm science and technology" that is developed to address problems associated with poverty in developing countries. ${ }^{1-3)}$

Appropriate technology was pioneered in 1973 by E.F. Schumacher, a well-known British economist. With his phrase "Small Is Beautiful," he argued that mass production technology disrupts the ecosystem and wastes rare resources; he suggested production by the masses that aims to conserve non-renewable resources by making good use of modern knowledge and experience, and by inducing decentralization. This technology was named "intermediate technology" because it is significantly superior to indigenous technologies of underdeveloped countries but is still cheaper

\footnotetext{
Corresponding author: Kwang-Taek Hwang

E-mail : kthwang@kicet.re.kr

Tel : +82-31-645-1431 Fax : +82-31-645-1488
}

and modest compared to the latest technologies. ${ }^{4)}$ However, the term was discarded in favor of the term "appropriate technology" because the former may be interpreted as suggesting that the technology was inferior to advanced (or high) technology.

In this study, to adhere to the concepts and principles of intermediate technology or appropriate technology, a filter for water treatment and a non-electric water treatment system were developed by using raw materials locally available in Cambodia. To that end, the process to make Onggi, Korean traditional earthenware whose micro-porosity and good air permeability allow excellent performance in fermenting and storing food, was employed. ${ }^{5-7}$ Onggi is known to have a porous body that shows air and water permeability thanks to the fact that the raw materials used to make Onggi have a large particle size distribution and a low sintering temperature, resulting in little densification between particles. $\left.{ }^{89}\right)$ Based on this knowledge, raw materials available locally in Cambodia were mixed into a clay body, which was then used to fabricate Onggi filters. After that, the filters were heat-treated, and their porous characteristics as well as filtration performance were investigated.

\section{Experimental Procedure}

\subsection{Fabrication of Onggi filters for water treatment and establishment of infrastructure}

To build a system in which Onggi filters for water treatment can be heat-treated, a wood-fired kiln, as shown in Fig. 1, was built at a site in Cambodia. The kiln was $174 \mathrm{~cm}$ wide, $351 \mathrm{~cm}$ long and $162 \mathrm{~cm}$ tall, and its walls were 23.5 $\mathrm{cm}$ thick. It was designed to prevent deformation due to 

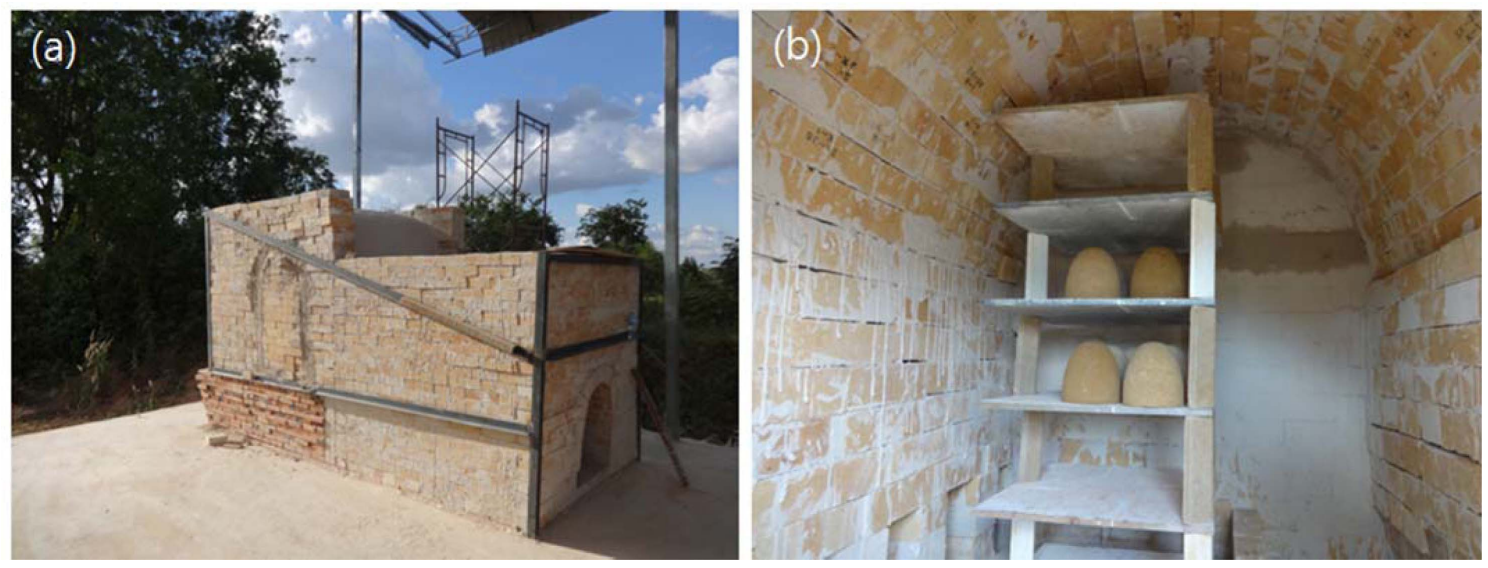

Fig. 1. (a) Traditional wood firing kiln and (b) inside of the kiln constructed in Cambodia.

shrinkage and expansion caused by repeated heat treatment. At first, the Onggi filters were made manually by collecting raw materials locally in Cambodia, but the resulting products turned out to be uneven in terms of size and shape, and so a fabrication system consisting of a grinder, a mixer, a pugmill, and a manual jiggering machine (shown in Fig. 2) was built instead to make Onggi filters. Due to the unstable power supply in Cambodia, the jiggering machine was made to be operated manually by two people. As shown in the diagram in Fig. 2, one person rotated the plaster mold by spinning the power handle from left, while the other person moved the head part in the path of the handle downward, so that the clay body for Onggi inside the plaster mold could be formed into a dome shape with even thickness.

To make Onggi filters, local red and yellow soil were first pulverized. Then, the raw materials after pulverization were added to the mixer with mass ratios of the red and yellow soil of 1:3, 1:4, and 1:5; these were mixed for about 30 minutes in a dry state without adding water. After 30 minutes, water at a volume of one-fifth of the entire volume was added and the clay body was further mixed 4 to 5 times in the pugmill. The clay body obtained from the pugmill had an even hardness of 6.5 , which was set using a clay hard- ness tester. Then 500 grams of clay with even hardness was added to the manual jiggering machine and formed into a hollow, dome-shaped filter. Onggi filters made in this way were $10 \mathrm{~cm}$ in diameter, $10 \mathrm{~cm}$ tall, and $1 \mathrm{~cm}$ thick; their surface area was $215 \mathrm{~cm}^{2}$. They were dried for two days in the shade. The dried Onggi filters were then heat-treated at 900,1000 , and $1100^{\circ} \mathrm{C}$ in the wood-fired kiln and their porosity levels were compared afterwards.

\subsection{Analysis of Onggi filters for water treatment}

To analyze the characteristics and properties of the raw materials used to make Onggi, the samples were first naturally dried in an oven at $100^{\circ} \mathrm{C}$ and then analyzed using inductively coupled plasma (ACE, NTM Co., USA). In addition, to examine the raw materials prior to making Onggi, and the crystal phase of the Onggi filters after heat treatment, samples were pulverized for 30 minutes using mortar for concomitant measurement by X-ray diffraction (D-max 2500, Rigaku, Japan). Then, to analyze the particle sizes of the raw materials (red oil and yellow soil), a dry sieving method was employed to separate the soils, each weighing 100 grams, by using six different sieves $(425,300,150,75$, 45 , and $20 \mu \mathrm{m})$. Using a particle size distribution analyzer
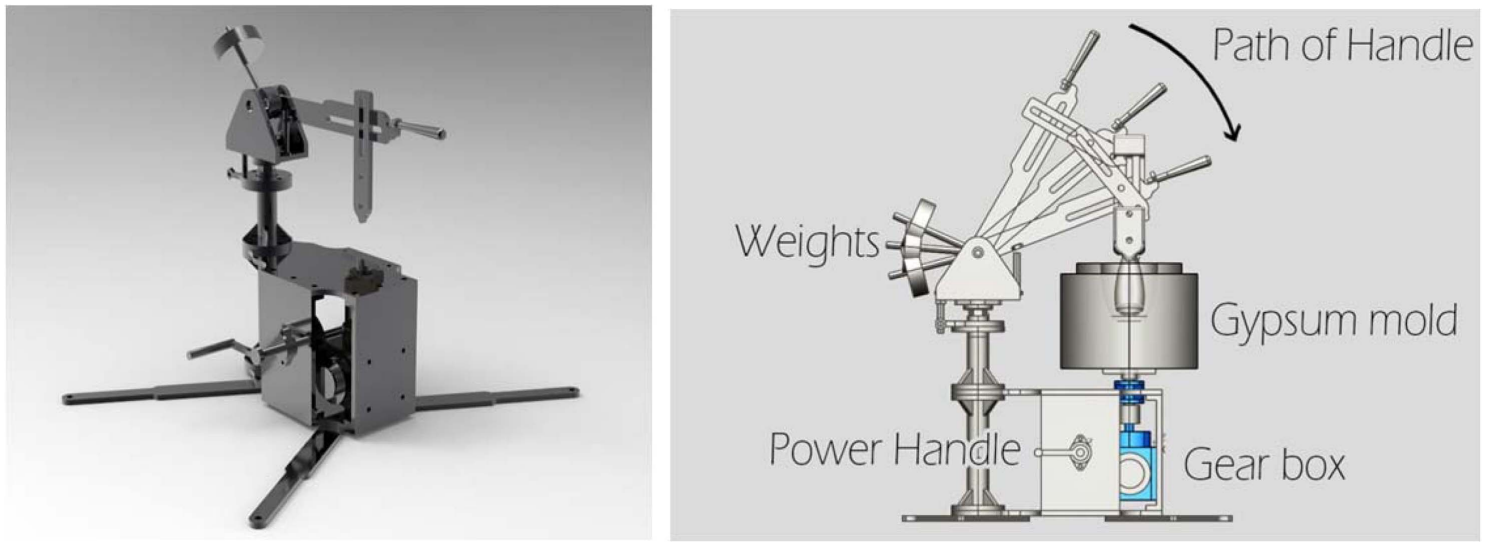

Fig. 2. 3D rendering image and schematic diagram of jiggering machine. 
Table 1. Chemical Composition of Raw Materials for Onggi Water Treatment Filter

\begin{tabular}{cccccccccc}
\hline Component (wt\%) & $\mathrm{SiO}_{2}$ & $\mathrm{Al}_{2} \mathrm{O}_{3}$ & $\mathrm{Fe}_{2} \mathrm{O}_{3}$ & $\mathrm{CaO}$ & $\mathrm{MgO}$ & $\mathrm{K}_{2} \mathrm{O}$ & $\mathrm{TiO}_{2}$ & $\mathrm{P}_{2} \mathrm{O}_{5}$ & $\mathrm{LOI}(\%)$ \\
\hline Red soil & 40.69 & 14.11 & 7.25 & 9.29 & 4.40 & 0.41 & 0.57 & 0.01 & 23.28 \\
Yellow soil & 46.19 & 13.27 & 8.23 & 6.54 & 4.78 & 0.20 & 0.55 & 0.01 & 20.23 \\
\hline
\end{tabular}

*LOI : Loss Ignition

(LA-950V2, Horiba, Japan), soil smaller than $20 \mu \mathrm{m}$ after dry sieving was measured for its particle size. Then, the porosity and pore size of the Onggi filters fabricated through heat treatment in the wood-fired kiln were examined using a porosimeter (Autopore IV 9500, Micromeritics, USA). Furthermore, the surface of the Onggi filters was observed with a scanning electron microscope (JSM-6701F, Jeol, Japan).

\subsection{Evaluation of filtration performance of Onggi filters for water treatment}

The Onggi filters after heat treatment were installed in a non-electric water treatment system for the filtration test. A $45 \mathrm{~cm}$ tall, $20 \mathrm{~L}$ PET container whose inlet measures $15 \mathrm{~cm}$ and whose bottom is $27 \mathrm{~cm}$ in diameter was purchased to be used as the body for the non-electric water treatment system. A fabricated Onggi filter and charcoal to remove odor were placed inside the water treatment system. ${ }^{10-12)}$ Pressurization by a manual pump was used to make the contaminated water in the repository pass though the Onggi filter and the charcoal. After impurities in the water had been filtered out, the water was stored again in another repository. During the filtration test, the amount of water being filtered per unit time $\left(\mathrm{L} / \mathrm{m}^{2} \mathrm{~h}\right)$ was measured after installation of the Onggi filter in the non-electric water treatment system; this was followed by pressurization. A standard solution with turbidity of 100 NTU was used for the filtration test. The water filtered through the Onggi filter was measured for turbidity and total dissolved solids (TDS) using a turbidimeter (model 2100NM, Hach company, USA) and a TDS meter (HI 4521, Hanna instruments, USA), respectively.

\section{Results and Discussion}

\subsection{Analysis of raw materials for Onggi filters for water treatment}

Table 1 presents the outcomes of the chemical component analysis of the local raw materials (red and yellow soil) from Cambodia that were dried for $24 \mathrm{~h}$ in an oven at $100^{\circ} \mathrm{C}$. The main component of both soils was $\mathrm{SiO}_{2}$, with each containing $40.69 \%$ and $46.19 \%$ of this compound. The red soil's $\mathrm{SiO}_{2}$ content was relatively lower than that of the yellow soil, but the red soil's $\mathrm{Al}_{2} \mathrm{O}_{3}$ content was $14.11 \%$, which was higher than that of the yellow soil at $13.27 \%$; this gave the red soil a higher performance in raising the fire resistance of the Onggi filter, whose $\mathrm{SiO}_{2}$ content is low. $\mathrm{Fe}_{2} \mathrm{O}_{3}$, a chromogenic oxidized substance for Onggi, was present at $7.25 \%$ and $8.23 \%$ in the red and yellow soils, respectively, both of which values were dramatically higher compared to the contents found in Korean celadon and white porcelains. ${ }^{13)} \mathrm{CaO}$
Table 2. Particle Size Distribution Analysis of Raw Materials for Onggi Water Treatment Filter

\begin{tabular}{ccc}
\hline Aperture & $\begin{array}{c}\text { Red soil } \\
\text { (wt \%) }\end{array}$ & $\begin{array}{c}\text { Yellow soil } \\
\text { (wt \%) }\end{array}$ \\
\hline$>425 \mu \mathrm{m} \uparrow$ & 26.85 & 54.02 \\
$300 \sim 425 \mu \mathrm{m}$ & 11.24 & 10.29 \\
$150 \sim 300 \mu \mathrm{m}$ & 26.0 & 15.15 \\
$75 \sim 150 \mu \mathrm{m}$ & 28.38 & 10.85 \\
$45 \sim 75 \mu \mathrm{m}$ & 5.02 & 4.8 \\
$20 \sim 45 \mu \mathrm{m}$ & 1.18 & 4.2 \\
$<20 \mu \mathrm{m}$ & 0.18 & 0.37 \\
\hline Total & 100 & 100 \\
\hline
\end{tabular}

is also a major chemical component whose content was higher in the red soil at $9.29 \%$ than in the yellow soil at $6.54 \%$. CaO mainly exists in the form of either anorthite or limestone (calcite), and serves as a fusing agent for clay, along with alkali ions. ${ }^{14,15)}$

Particle sizes of the raw materials (red and yellow soil) from Cambodia were analyzed to determine the difference in particle size distribution between the two soils. Because Onggi filters are created using these natural raw materials, controlling their particle sizes is essential in maintaining consistency of the filter characteristics. As indicated in Table 2, the raw materials were separated by particle size through overall dry sieving, and each particle size group was weighed. Fig. 3 shows the raw materials, each obtained using dry sieving. Sieved particles smaller than $20 \mu \mathrm{m}$ were collected separately and their particle sizes were measured using the particle size distribution analyzer. The measurement results are shown in Fig. 4, along with the values of D10, D50, and D90, and the mean size. Both materials have a particle size distribution in bi-modal form. Unlike the red soil, whose particle size ranged from 75 to $300 \mu \mathrm{m}$, particles in the yellow soil that were bigger than $425 \mu \mathrm{m}$ accounted for most of the soil weight, followed by particles in the range of 150 to $300 \mu \mathrm{m}$. Therefore, it can be said that the yellow soil particles were relatively bigger than the red soil particles, indicating that the red soil contained more particles with smaller particle diameter than did the yellow soil.

The smallest particles after sieving were analyzed for their size; the results are shown in Fig. 4. Unlike the yellow soil, the red soil has a bi-modal form with particles ranging from 0.1 to $1 \mu \mathrm{m}$ and from 1 to $20 \mu \mathrm{m}$, while the mean particle size was $6.27 \mu \mathrm{m}$. The yellow soil has a small amount of particles in the range of 0.2 to $0.3 \mu \mathrm{m}$, but they are mostly in a mono-modal form, with a mean particle size of $10.38 \mu \mathrm{m}$. 


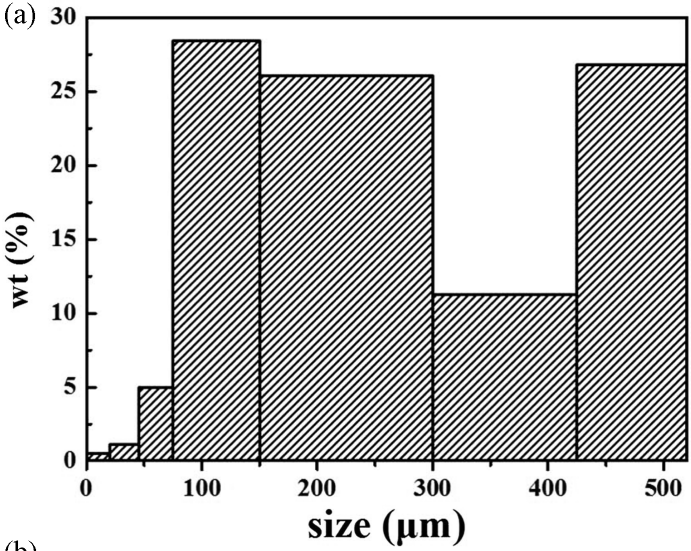

(b)

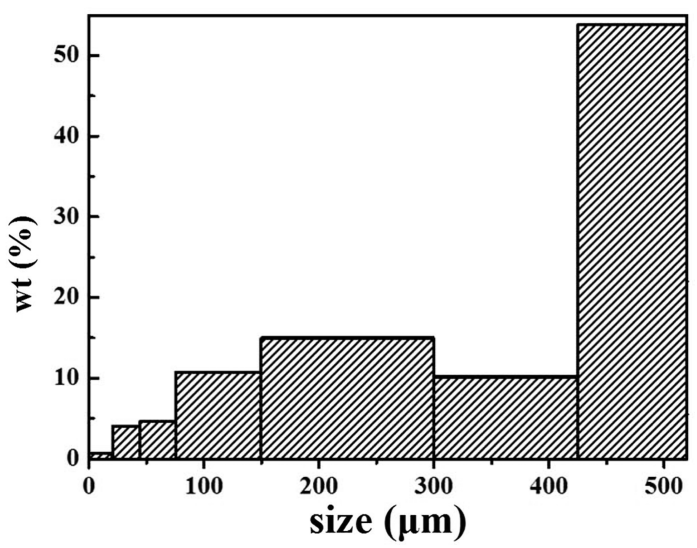

Fig. 3. Particle size distribution of raw materials; (a) red soil, (b) yellow soil.

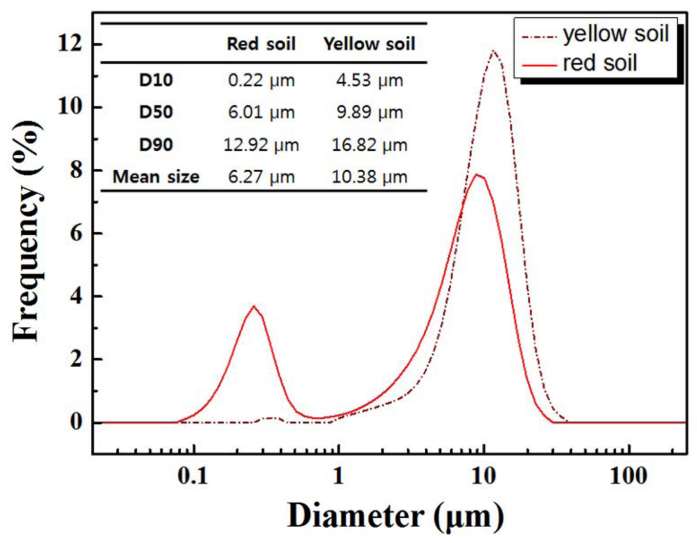

Fig. 4. Particle size distribution of raw materials under 20 $\mu \mathrm{m}$.

Therefore, through the values of D10, D50, and D90, and the mean size, the red soil was found to have smaller particles overall than the yellow soil. These small particles play a role of a plasticizer during the molding process of Onggi filters and ensure moldability, whereas the yellow soil with many large particles is responsible for forming pores in the filter. ${ }^{5)}$

The heat-treated Onggi made with a mixture of the red and yellow soil was measured using X-ray diffraction for
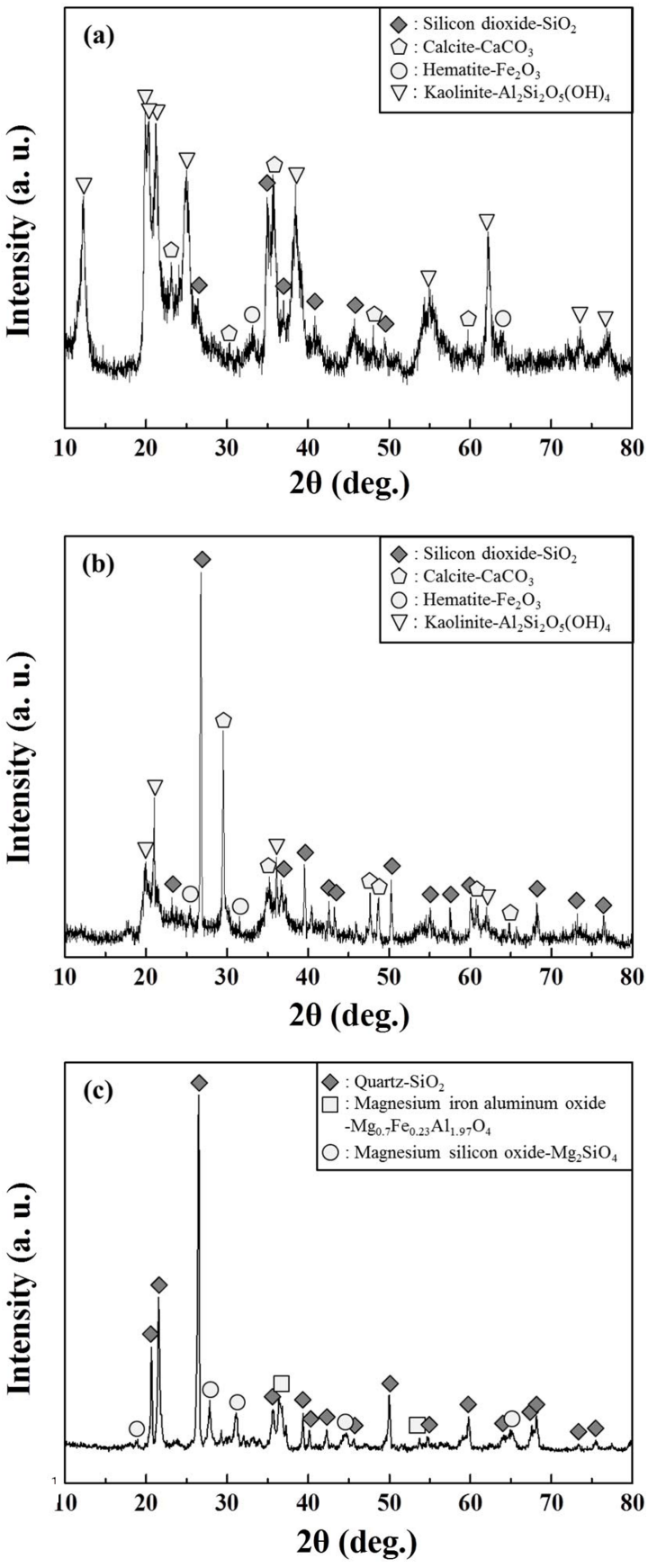

Fig. 5. X-ray diffraction patterns of raw materials; (a) red soil, (b) yellow soil, (c) Onggi (heat treated).

crystallographic analysis; the results are shown in Fig. 5. Silicon dioxides, generally found in clay raw materials, exist in both the red and yellow soil, and they are responsible for forming a frame. ${ }^{\text {9) }}$ Calcite and hematite are crystal phases commonly found in both soils. Calcite is a raw material in white lump form that serves as a fusing agent. Hematite is what makes the entire Cambodian soil look red, and is typically found in large quantities in the clay used for Onggi. One crystal phase that displayed different characteristics between the two soils is kaolinite, which is known for plas- 

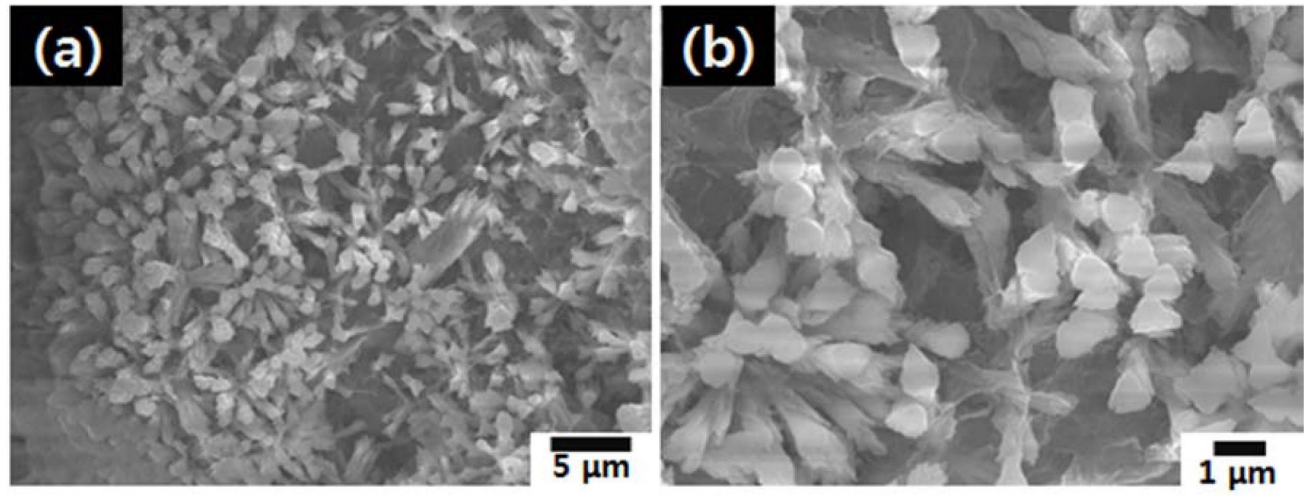

Fig. 6. SEM images of (a) Onggi filter surface and (b) magnified image.

ticity and was found more in the red soil. For an Onggi filter to have good filtration performance, the two materials for the framework and the plasticity must be mixed for use at varying mixing ratios. In an Onggi made with the two raw materials mixed together and heat-treated, quartz was measured and found to be at the main peak, while a peak was found in the reaction phases of $\mathrm{MgO}, \mathrm{SiO}_{2}$, and $\mathrm{Fe}_{2} \mathrm{O}_{3}$ after heat treatment.

Filters were molded by adjusting the mixture ratios of the red and yellow soil to 1:3, 1:4, and 1:5. Then, the filter properties, particle sizes, and crystal phases were analyzed. The red soil that had a large quantity of clay crystals ensured a filter's moldability, whereas the yellow soil's main crystal phase was $\mathrm{SiO}_{2}$, which was responsible for the filters' frame. When treating water using an Onggi filter, higher porosity leads to greater filtration capability, and thus the yellow soil that forms the frame is needed in greater quantity. However, an increased amount of yellow soil can translate to lower plasticity, resulting in cracks forming on the filter. When the clay ratio of the red and yellow soil was 1:5, the filter displayed cracks on its surface after being molded in the manual jiggering machine. On the contrary, when the ratios of the red to the yellow soil were $1: 3$ and 1:4, the filters were molded without cracks. The molded form was heat-treated at $1000^{\circ} \mathrm{C}$, after which its porosity was measured based on Archimedes' principle. When the ratio was $1: 3$, the Onggi's porosity was $25.15 \%$, whereas it was $30.40 \%$ when the ratio was $1: 4$, indicating that the latter ratio with its higher porosity, is the optimal ratio.

Onggi filters made with the optimal ratio of the red and yellow soil of 1:4 were heat-treated for one hour at 900, 1000 , and $1100^{\circ} \mathrm{C}$, after which their respective porosity was measured. The filter heat-treated at $900^{\circ} \mathrm{C}$ had a porosity of $30.55 \%$, while porosity of the specimen heat-treated at $1000^{\circ} \mathrm{C}$ was $30.40 \%$, representing a minor difference. However, the porosity dropped to $20.51 \%$ for the filter heattreated at $1100^{\circ} \mathrm{C}$, indicating that densification between particles was occurring. Based on this measurement, it was determined that $1000^{\circ} \mathrm{C}$ was the optimal temperature for heat treatment as it is the highest possible temperature for heat treatment that results in high porosity, enabling the
Onggi filter to maintain its strength when used in a water treatment system and to increase the filtration capability.

\subsection{Property analysis of Onggi filters for water treat- ment and filtration performance evaluation}

The Onggi filters were heat-treated at $1000^{\circ} \mathrm{C}$ to ensure low shrinkage and high porosity. ${ }^{16)}$ Fig. 6 shows the microstructure of the filters made with dried Onggi after heattreatment at $1000^{\circ} \mathrm{C}$; microstructure was observed with a scanning electron microscope. It was confirmed that the Onggi filters had low shrinkage and high porosity; the particles on the surface had a range of diameter of $0.5-1 \mu \mathrm{m}$ and were in a floral shape. Also, pores of about $2 \mu \mathrm{m}$ in diameter were found to be evenly distributed all over the filters. In addition, mercury intrusion was performed to measure the mean pore size and porosity in the path that actual contaminated water would pass through, in order to see if the filter was adequate for water treatment in connection with the microstructure. Fig. 7 shows the porosity and pore distribution as measured with mercury intrusion. It was found that the mean pore size of the filter was $2.97 \mu \mathrm{m}$ and the porosity was $29.06 \%$. Because a filter for water treatment is created using a raw material with a narrow particle size distribution, the pore size distribution is controlled to be narrow. ${ }^{17)}$ However, when a natural raw material is used, the size dis-

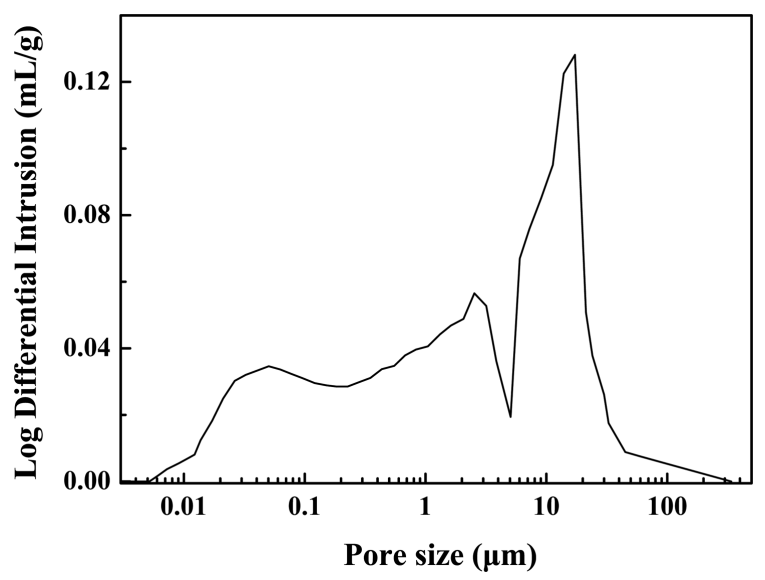

Fig. 7. Pore size distribution of Onggi filter fired at $1000^{\circ} \mathrm{C}$. 


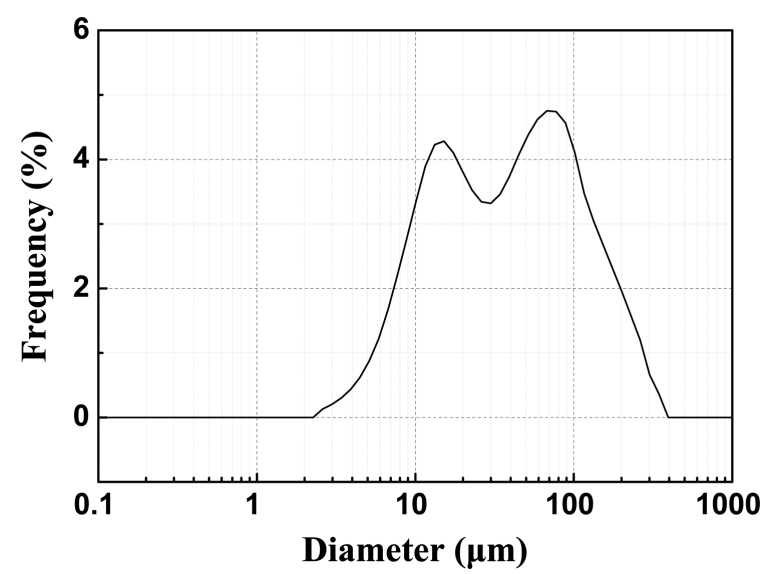

Fig. 8. Particle size distribution of turbidity standard solution (100NTU).

tribution of the raw material is wide, as shown in Fig. 3 and Fig. 4; thus, the filter after heat-treatment had a wide pore size distribution. Because a structure with a wider pore distribution, when applied to a filter, may have low filtration capability, porosity needs to be raised as high as possible.

The filtration performance evaluation of the final Onggi filter was carried out using a standard solution to measure turbidity. The turbidity standard solution was made to have a turbidity of $100 \mathrm{NTU}$; the particle sizes in the solution were measured by the particle size distribution analyzer, with results as shown in Fig. 8. The solution, in which $1 \mathrm{~g}$ of Cambodian clay was mixed with $5 \mathrm{~L}$ of distilled water, was in a bi-modal form and its mean particle size was $57.55 \mu \mathrm{m}$. In Cambodia, rainwater is gathered in ponds and puddles, mixed with clayey raw materials, and typically has high turbidity. This outdoor water is filtered and used for drinking. Therefore, when creating the standard solution, raw materials from Cambodia were used to make the water quality as similar to the actual water for filtering as possible. As shown in Fig. 8, the particles distributed in the standard solution ranged from small ones of about $1 \mu \mathrm{m}$ in diameter to much larger ones of about $350 \mu \mathrm{m}$. As the pore size distribution of the Onggi filter is also wide, it was decided that the Onggi would be able to filter out the distributed particles.

The filtration performance of the fabricated Onggi filter using the standard solution was measured and results are shown in Table 3. The turbidity and TDS were 100 NTU and $10.4 \mathrm{mg} / \mathrm{L}$, respectively, but they decreased to $0.2 \mathrm{NTU}$ and $9.2 \mathrm{mg} / \mathrm{L}$ after filtration. These figures satisfy the standards for drinking water, indicating that the Onggi filter can filter out contaminants from water to make it adequate for drinking.

Figure 9 shows the non-electric water treatment system and the turbidity standard solution before and after water treatment. The system was comprised of two affordable containers and a plastic part where the Onggi filter and charcoal were stored, as shown in Fig. 9 (a). The Onggi filter was glued to the plastic part to filter out suspended particulate
Table 3. Performance of Onggi Water Treatment Filter Using Turbidity Standard Solution (100 NTU)

\begin{tabular}{cccc}
\hline & $\begin{array}{c}\text { Quality standard } \\
\text { for } \\
\text { drinking water }\end{array}$ & $\begin{array}{c}\text { Turbidity } \\
\text { standard } \\
\text { solution }\end{array}$ & $\begin{array}{c}\text { Treated } \\
\text { water }\end{array}$ \\
\hline Turbidity (NTU) & 1.0 & 100 & 0.2 \\
TDS (mg/L) & 500.0 & 10.4 & 9.2 \\
\hline
\end{tabular}
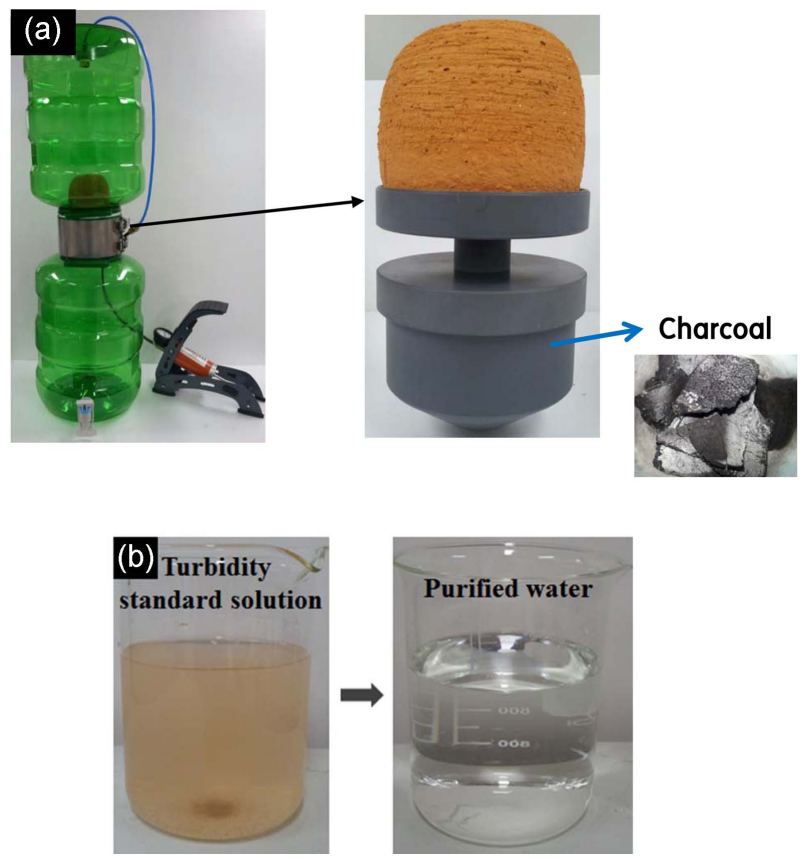

Fig. 9. (a) Non-electric water purifier with Onggi filter and (b) filtration test.

matter contained in the original water, and then the filtered water was made to pass through the charcoal underneath. The odor from the water is removed by absorption. While most water treatment systems use activated carbon for odor removal, plain charcoal was used for this study as it is easily available in Cambodia. The $5 \mathrm{~L}$ turbidity standard solution was treated through the well-fabricated Onggi filter in the non-electric water treatment system, after which time the water's turbidity and permeability were measured. As per The Rules on Water Quality Standards for Drinking Water and on Inspection, drinkable water should have turbidity of 1 NTU or below and less than $500 \mathrm{mg} / \mathrm{L}$ of TDS. The $\mathrm{pH}$ values before and after filtering the turbidity standard solution were 7.8 and 7.9, respectively, indicating little change, while the permeability was measured at 31.63 LMH. The turbidity decreased by $99.8 \%$ from 100 NTU to less than 0.2 NTU. Meanwhile, TDS fell by about $12 \%$ from $10.4 \mathrm{mg} / \mathrm{L}$ to $9.2 \mathrm{mg} / \mathrm{L}$. As for E. coli, which is a cause for water-borne diseases, specimens of the original water from Cambodia and the treated water were sent to the RDI Resource Laboratory for water quality analysis, and it was found that $E$. coli, which was present at $20 \mathrm{cfu} / 100 \mathrm{~mL}$ in the original untreated water, had been completely removed. 
Furthermore, the suspended particulate matter found in the original local water accumulated on the Onggi filter's surface (fouling) while the water treatment system was in use, resulting in reduced filtration capability. This problem can be solved by cleaning the filter, and for an Onggi filter, a common household dish sponge can be used to recover the filtration capability, thereby ensuring long-term utilization of over six months of the Onggi filter. Currently, water treatment systems equipped with an Onggi filter are being introduced to households in Cambodia.

\section{Conclusions}

In support of "appropriate technology," and in order to remove contaminants from water for drinking using membrane filtration technology, this study aimed to create Onggi filters using raw materials from Cambodia and evaluated the filters' performance. The study helped cut down the price of filters, which are consumable parts of a water treatment system, by making them with natural raw materials. Onggi filters with porosity and adequate filtration performance were fabricated using a clay mixed with two types of raw materials for frame and plasticity; materials were then molded with a manual jiggering machine and heat-treated for one hour at $1000^{\circ} \mathrm{C}$. The study verified the optimal composition for the fabrication of uniform Onggi filters without cracks; the porosity and the mean pore size of the Onggi filter were found to be $29.06 \%$ and $2.97 \mu \mathrm{m}$, respectively. To test the Onggi filter's performance, a non-electric water treatment system was built. Water filtered through this system at a rate of $31.63 \mathrm{~L} / \mathrm{m}^{2} \mathrm{~h}$. The turbidity of the standard solution fell by $99.8 \%$ from 100 NTU to 0.2 NTU, while TDS also decreased from $10.4 \mathrm{mg} / \mathrm{L}$ to $9.2 \mathrm{mg} / \mathrm{L}$, which is about $12 \%$ lower compared to the original turbidity standard solution. In addition, E. coli, which causes water-borne diseases, was present at $20 \mathrm{cfu} / 100 \mathrm{~mL}$ in the original water but, after filtration treatment, it was found to have been completely removed. Water treatment systems equipped with an Onggi filter are being introduced to Cambodian households.

\section{REFERENCES}

1. G. I. Davies, L. McIver, Y. Kim, M. Hashizume, S. Iddings, and V. Chan, "Water-Borne Diseases and Extreme Weather Events in Cambodia: Review of Impacts and Implications of Climate Change," Int. J. Environ. Res. Public Health, 12 [1] 191-213 (2014).

2. D. H. Jang, K. Y. Lim, and Y. W. Kim, "Effect of Additive
Composition and Content on Sintered Density and Compressive Strength of Cordierite Ceramics (in Korean)," J. Korean Ceram Soc., 44 [4] 230-34 (2007).

3. M. A. Alvin, T. E. Lippert, and J. E. Lane, "Assessment of Porous Ceramic Materials for Hot Gas Filtration Application," Am. Ceram. Soc. Bull., 70 [9] 1491-98 (1991).

4. J. T. Kim and S. W. Hong, "What is Appropriate Technology?," Korean Ind. Chem. News, 17 [1] 38-50 (2014).

5. S. S. Hong, Breathing Pottery, Onggi (in Korean); pp. 16869, Ed. M. J. Kim, Booksea, Paju, 2010.

6. K. I. Han, M. J. Kim, H. J. Kwon, Y. H. Kim, and M. D. Han, "The Effect of Container Types on the Growth of Bacteria during Kimchi Fermentation," Korean J. Food Nutr., 26 [2] 249-57 (2013).

7. S. H. Kim, "Porous and Pottery with Dark Brown Glaze," J. Contents Association, 7 [10] 157-64 (2007).

8. G. H. Koo, "A Study on the Korea Tradition Onggi," J. Education Studies, 1 [49] 233-251 (2012).

9. W. S. Cho, "Scientific Analysis of Onggi and its Porous Characteristics (in Korean)"; pp. 141-45 in Proceeding of the Onggi Expo Ulsan Korea. Ulsan, 2009.

10. S. A. Kim, J. S. Hong, J. K. Suh, and J. M. Lee, "A Study on the Characteristics and Surface Modification of the Zeocarbon for Water Treatment," Carbon Lett., 6 [3] 166-72 (2005).

11. S. H. Kim and B. M. Min, "Mathematical Modeling of BioPhysico Chemical Processes in Activated Carbon Columns," Korean J. Chem. Eng., 10 [1] 18-27 (1993).

12. J. K. Jeong, Y. W. Kim, H. S. Choi, D. S. Lee, S. A. Kang, and K. Y. Park, "Increased Quality and Functionality of Kimchi When Fermented in Korean Earthenware (Onggi)," Int. J. Food Sci. Technol., 46 [10] 2015-21 (2011).

13. K. K. Choo, W. K. Choo, S. D. Ahn, Y. E. Lee, G. H. Kim, and Y. S. Lee, "A Study of the Chemical Composition of Korean Traditional Ceramics : Celadon and Koryo Whiteware", J. Conserv. Sci., 26 [3] 213-28 (2010).

14. Y. Pontikes, G. Kerckhofs, U. Kim, C. Rathossi, G. Mertens, W. S. Cho, M. Wevers, and B. Blanpain, "Microstructure, crystalline phases and pore morphology of Onggi"; pp. 1-4 in Proceedins of the 12th Conference of European Ceramic Society. Stockholm, Sweden, 2011.

15. S. M. Kim, H. G. No, U. S. Kim and W. S. Cho, "A Study on Sources of Pore Formation in Onggi via the Comparison with Porcelains," J. Korean Ceram. Soc., 51 [1] 11-8 (2014).

16. I. H. Wi, D. W. Shin, K. S. Han, J. H. Kim, W. S. Cho, and K. T. Hwang, "Characteristics of the Non-Electric Water Purification System Using Onggi Filter," J. Korean Ceram. Soc., 51 [4] 332-36 (2014).

17. S. Kroll, L. Treccani, K. Rezwan, and G. Grathwohl, "Development and Characterization of Functionalized Ceramic Microtubes for Bacteria Filtration,” J. Membr. Sci., 365 [1] 447-55 (2010). 